\title{
Towards the construction of compulsory education of boys and girls in Maasai pastoral community
}

\author{
Caroline Marygorety Akinyi Otieno \\ African Women's Studies CentreUniversity of NairobiNairobi, Kenya.
}

\begin{abstract}
This study aimed at determining the spread of non-schooling and dropout rate, portrait of conditions, causes, solutions. The qualitative study focused on Maasai pastoral community in the marginalized regions (remote/isolated/alienated and the poor). The findings showed that the lives of the learners are so apprehensive concerning pastoralism, parent's socio-economic condition, distance to school and socio-cultural practices. The causes are complex both from internal and external problems of the learners. Besides, the crucial problems such as lack of uniform, repeating classes and gender roles. It is recommended that the 'dormitories' be constructed for girls who have undergone the rite of passage, delaying moranism to a later date and most important to construct compulsory education comprehensively to address these factors.
\end{abstract}

Key words: Pastoral community, non-schooling/dropouts, construction, education

\section{INTRODUCTION}

The Kenyan Maasai is a pastoral society that lives in a vast arid and semi-arid land (ASAL) that straddles the Kenya-Tanzania border. They make up $0.7 \%$ of Kenya's population with a similar number living in Tanzania. Their distinctive culture has made them one of East Africa's most internationally famous people. The society exhibits a great love and concern for livestock especially cattle (Ronoh, 2008). Maasai people's lifestyles revolve around animal husbandry and related activities. This cultural inclination is a product of unfavorable environmental factors as many parts of Maasailand are arid and semi-arid (Ronoh, 2008). As a result of the environmental condition Maasai are a semi-nomadic people who live under communal land management. They movement with livestock is based on seasonal rotation. The Maasai are among the communities in Kenya which continue to preserve their traditions and culture despite education civilization and western cultural influences. For instance the society has a barracks-like institution called the Murran system where male youths are formally trained in preparation for community life.

Their social cultural practices to some extent contribute to the high rate of school drop out rate and non-schooling. For example a study by Ronoh, Chiuri, Matheka, \& Bor, (2010) found that in the Murran curriculum male youth are taught Indigenous Knowledge, which contain comprehensive and diversified community-focused attributes that have profound effects on school attendance by male Maasai youths of Narok District. The attributes of Indigenous Knowledge learned during Maasai Murran system make male Maasai youths who had already enrolled in school to drop out and those who had never enrolled to shun school for good.

Another cultural practice derailing Maasai youth from formal education is the circumcision of girls most commonly referred to as female genital cutting or mutilation. The procedure is usually performed when the girls are between the age of eleven and thirteen. After circumcision they are considered to be women and therefore eligible for marriage leading to early marriages. According to Quick-Palmer, (2014) 37\% of girls are married before the age of eighteen and $16 \%$ are married before their fifteenth birthday in Tanzania. Whereas in Kenya, the rates for marriage before 18 years of age are $26 \%$ and $16 \%$ for under $15 \mathrm{~s}$. She further argues that apart from the cultural practices that cut down continuation of education for a Masaai girl child also economic factors do play a part. For the few exceptional girls who pass the national test to graduate from primary school (K.C.P.E), the yearly cost of secondary education is high for most Masaai. When the cost is affordable sons are almost always given priority.

One of the factor leading to early marriages for girls in Masaailand are the ecenomic gains to a family. The daughter marriage increases the wealth of the girl's family through the cattles and cash that are paid as dowries. Moreover, when a girl is married she relieve the family the economic burden of supporting her, thereby increasing the willingness of fathers to let their doughters to marry when they are at a younger age. Early marriage is often cited as the main reson Masaai girls drop out of school (Quick-Palmer, 2014).

Another reason leading to non-schooling is the training during circumcision. Girls are taught that circumcision is a rite of passage into womanhood that accompanies puberty and an immediate precursor to marriage. 
Therefore, once circumcised they are rediculed by their peers if they continue with their education because the school is associated with children.

The fear of premarital pregnancy and early pregnancy is the second reason most girls drop out of school. In the Masaai culture once a child becomes nine years old they cease staying the same house with the father and instead sleeps in a separate house without supervision. A practise which applys to girls who are not informed about how a woman becomes pregnant. This ignorance combined with lack of supervision makes the girls highly vulnerable to becoming pregnant before marriage. The premarital preganancy does not only make the girl drop out of school but also brings disgrace to a family and leads to a reduced bride price.

Maasai Association (2015) argues that the number of primary and secondary school in Masaai region is very low while colleges are unheard. They further contend that the Masaai region has the highest primary and secondary school droup out rates in Kenya. Quick-Palmer, (2014) add that since the pastoral Maasai require a vast land resources to graze their cattles villages a constructed further apart from each other. As a result one school usually serves several villages, which are within a 15-20 Kilometers radius. Since there are no cars, buses, horses or even bicycles available in most part of Maasai land children have to walk long distances to reach the nearest school. Many parent are corncerned about the security of their children and therefore fails to enrol their child to school.

To those who make to school the long distance undermines education. Teachers reports that children who have spent two to five hours walking to school in the morning are tired and their ability to concentrate is impared. Also, when they arrive at home after the long walk it is often late yet they are required to do other chores. To those who have energy and desire to read after accomplishing their home responsibilities, it is usually dark and because of lack of electricity or artificial light many may not be able to study.

The maasai are pastoral-nomadic society and sometimes circumstances requires families to move from one place to another in search of grass and water for their cattles especially in dry seasons. During this time a child education is often interrupted until when the rain comes. This makes the school going children to lag behind whereas others opt to stop attending school altogether.

The maasai children who attends school usually enrolls to the free public schools. Unfortunately in Kenya, all students are required to wear uniforms, which many families can not afford. Additionally, for the high school students parent are required to buy books and pay fees for the upkeep of their children at school. Those who can not afford these school expenses usually do not complete their education and this contributes to the drop out rate of students.The above discussed factors contributes to the high rate of illiteracy in Maasai land. This is despite the report by the ministry of finance and planning in Kenya stating that illiteracy is the major cause of poverty in Maasai land. The report further add that education is the best way that can overcome poverty, increase income, improve health and nutrition, reduce family size as well as enriching the quality of their lives (Maasai Girls Education Fund, 2014).

\section{METHODOLOGY}

This study will review the related literature concerning the drop out rate and non-schooling in Maasai pastoral community. The literature to be reviewed will involve the causes of drop out rate in Maasai land, the conditions fueling the high rate of drop out and the solution to curb this trend. Sources for the literature used in this study are from articles, books, internet sources. The researcher relied on the previous literature because there are a number of articles that presents the causes of high drop out rate in Maasai land.

\section{RESULTS}

Each society will strive to perpetuate its culture to the next generation through education. Obaya (2005) asserts that every human society regardless of its level of technical evolution will devote a great attention to transmitting its cultural heritage to the young (Obanya, 2005). He allude that education was first threatened by its nature of schooling because most societies questioned the effectiveness of education their children receive at school. WHO (2011) add that since the time education was introduced the traditional African societies took it for granted because the formal educational setting that was introduced did not meet the need and aspiration of the African societies and act of formal schooling was non-African. Most African societies desired an education that keeps them psychologically in their socio-cultural frame, contrary to education that is equated to schooling. The educational system that was introduced was formulated by colonialist who had a cultural background different to that of African. Even after independent the reforms in African education that were conceived and implemented were closely tied to European setting. The reason behind this was because even though african are politically independent, technologically and economically African depend on countries that colonised them. Therefore, the reforms that were introduced after departure of the colonizers were tied to the grants given by these Europeans countries. This led to education system that did not incorporate the African culture, their values, norms and traditions. It led to rejections of the schooling system by some African societies because the 
formal education that was introduced was against some of African cultural practices such as the femals genital mutilation (FGM).

Yara, (2012) argues that some of the cultural practices of pastoralist communities contribute to high rate of drop out and achievement of low quality grades by students. Yara further add that provision of quality education to children in a pastoral community is a nightmare. When girls reach puberty unwanted pregnancy and early marriages interfere with their academic performance and force them to drop out of school. According to a report by UNESCO, (2010) girls from marginalized areas are often sexually harassed due to the neglect by the government. It usually happens because girls have to travel long distances before they reach nearest school thus increasing the risks to their security.

Juma, Simatwa, \& Ayodo, (2012) point out that parent education and family interaction patterns during childhood have a direct link to the child's developing acedemic success and achievement-oriented attitudes. They futher argue that social learning and social-cognitive behavior is shaped in part through observational and direct learning experiences. Those experiences lead to the formation of internalized cognitive scripts, values, and beliefs that guide and maintain behavior over time.

Rotich, Rono, \& Mutisya, (2014) observes that after the initiation ritual of a Maasai girl her Psychosocial status is radically transformed. She now become a woman and majority of them opt to stick to their cultural ways at the expense of educational opportunities. The training that they undergo during the rite of passage to womanhood fosters an attitude that formal education through the school system belongs to the little uncircumcised girls. Therefore, after circumcision many Maasai girls drops out of school because of these attitudes that they develop. According to a study by Tobik, (2009) it is only $40 \%$ of the maasai children in rural areas that have attended formal schools and only $8 \%$ of all girls in rural areas of Maasailand have had a chance to complete secondary school education. The Maasai Association further adds that the greatest hindrance to girls receiving an education is that they are being sold into early marriage after undergoing FGM. The parents neglect the education of the girl child so that she drops from school and get married. Early marriage is a barrier to girls education, since they are forced to drop out of the school.

The study by Rotich, Rono, \& Mutisya, (2014) reveals that parents in Maasai land especially in Narok County fears that their daughters may drop out of school due to premarital pregnancy. Secondly, they fear that educating their daughter will transfer the family wealth to their marital homes. Thus, parent are reluctant to pay school fees and to provide less attention to the girl child education.

To cope with their environment and ascertain sustenance of their survival Maasai conduct training and learning experiences through the medium of Indegenous Knowledge (IK). The IK curriculum contain useful skills, values and attitudes that make a Maasai male who have undergo the training become a functional member of the society. The training usually start after circumcision to young Maasai boys, who are taught how to live in the harsh environmental conditions (Ronoh, 2008).

Ronoh argues that the pastoral economy and lifestyle of the Kenyan Maasai contributes to the society's resistant to change and adoption of the formal education. He further contend that the irrelevance of the school based education to pastoral people's live have led to the Maasai resistance to educational change. The indigenous learning and training were meant for living and survival.

\section{THE MURRAN SYSTEM OF THE KENYAN MAASAI}

The Murran system is an impregnable Maasai institution that arises from deliberate instructional processes related to worriorhood among other subjects. These processes entails indigenous learning and training experiences that emphasise the importance of the institution as an identity of Maasai society. Moreover, the members of the murran serves as the community defence force. The murran system is a stage onto which Maasai youth enter after circumcision to be trained on IK and experiences that will enable them to survive in the hash environmental conditions. The curriculum has been taking six or seven years but at present it takes two to three years.

The Murran system is a tradition that adolescent Maasai boys yearn to enter. It has been observed that as the craving to join the system increases majority of school-going Maasai boys display abrupt disinterest in the school. The subjects offered in the Murran system enhance both communalistic as well as individualistic values. The Murranism is a significant pubescent stage in the growth of Maasai boys. The circumcision rites for Maasai boys which comes prior to Murranism is conducted when they are between the early teens and mid twenties (Vavra, 1991). The learning and training activities in the Murran institution are formal, therefore, they are offered in school-like encampments called $i$-manyat (Singular: -manyatta), these training are highly diversified and relevant to community life.Ronoh (2008) observes that circumcision of Maasai boys serves as a stimuli to psyche them to yearn to join the Murran system stage. This yearning leads to a sudden disinterest in schooling. The study by Ronoh, Chiuri, Matheka, \& Bor, (2010) reveals that the boys who have not been circumcised they do not portray this craving to join Murran and majority of them perform better grades in the national 
examination than those who have undergone the rite of circumcision and are potraying marked disinterest in school.

\section{ATTRIBUTES OF INDIGENOUS KNOWLEDGE OF THE MURRAN SYSTEM}

The subjects offered at the Murran institution enhances several attitudes, values and develops certain skills. The civil education taught promotes and fosters patriotic values among the Maasai youth. They learn to be patriotic member of the society. Ronoh (2008) contend that the training in the institution incalcates to the Maasai youth a distinct love for their society a personality that is marked by unwavering loyalty and readiness to defend it at all costs. They are also taught to respect and obey their leaders. The civil education also fosters values of leadership and command in addition to the conflict resolution and reconciliation skills. To solve conflict properly the subject inculcates skills that enables Maasai male to examine carefully pieces of evidence availed. Also the art of effective communication through debates and stimulus variation such as use of gestures, intonation, inflection and body movements are also developed. Therefore, the youth develop commitment to solve problems facing the society and joy of debates and love for effectie communication skills (Ronoh, Chiuri, Matheka, \& Bor, 2010).

Another subject offered in the Murran curriculum is the social and family life. Important lessons in this subject include comradeship, corporate unity and social cohesion based on mutual trust and cordial relationship to each other. The subject enhances to the Maasai youth values of marital and civil responsibilities. In addition, the values of sharing among the Maasai are inculcated. They learn to share everything including water, food, company and even their wives. One of the most significant skill also taught in this subject are courtship and interpersonal relations. For instance, they will be taught the art of seduction as well as the techniques of courting women. The attitudes developed in Social and Family Life subjet among the Maasai worriors include desire and yearning to fulfilling the social responsibilities and commitment to sharing everything with the members of their age-set. There is no subject in the school based education that inculcates these important skill, values and attitudes as the Maasai IK curriculum does.

They are other subjects offered within the Murran institution, which include Economics, Productive art and Ecological/Environmental Studies. Ronoh (2008) assert that in Economics youth are taught the importance of becoming rich in livestock and skills for sustenance and expansion of this wealth. For instance, in animal husbandry they are taught identification of nutritious grass, herding and treatment of various diseases among other facets of keeping livestock. Military studies is another subject offered to Youth during the Murran system. In this subject they are taught the theory and practice of warfare. The values taught include warriorhood, military strategy, discipline and chain of command. They are taught how to defend and protect the community. In the Murran system Maasai instructors instill in the male Maasai youths the fear that School Based Education does not focus on any particular productive life, hence its irrelevance and subsequently persistent rejection by the society. The irresistibly exiting indigenous training engagements obviously cannot be accomplished when one is attending school. As a result, male Maasai youths who had enrolled in school earlier opt to drop out in order to pursue learning experiences provided under the auspices of the Murran system (Ronoh, Chiuri, Matheka, \& Bor, 2010).

Socialisation of Maasai males is another impendiment towards realization of school based education for all males. The Maasai males are taught at an early age to despise females as Mungata in Ronoh et al. (2010) put it "Older boys and men consider all women, including their mothers and lady teachers as inferior or simply children who should never have any control over them, let alone punish them". As a result of this older boys and men do not take lady teachers seriously. The circumcised Maasai boys despise women teachers and hate being instructed and punished by such teachers. At times, initiated Maasai school boys react violently towards women teachers who punish them, and very often, such boys drop out of school. Sonkori in Ronoh et al. (2010) narrates one of the incidence this way, "On the last day I went to school, 1differed with a woman teacher. She punished me by caning. 1 grabbed the cane, beat her and then I fled to join murranism, which I liked very much".

The fact that schools are staffed with female teachers and as long as the subjects offered under the Murran system continue to be relevant to life in Maasailand, male Maasai youths will continue to shun schools. Instead, many of them would rather join the Murran system and never to go back to schools if they had once been enrolled, than be taught and punished by female teachers. All the subjects taught to Maasai warriors under the Murran system have functional attributes, which enhance Maasai culture and identity. Most ofthese attributes have utilitarian qualities. Subjects offered through murranism are comprehensive and very relevant to life in Maasailand. Learning through these subjects is all-inclusive and strengthens ethnic cohesion, features that SBE scarcely performs. 


\section{DISCUSSION}

The research finding indicate diverse causes and conditions that contribute to the high rate of school drop out in Maasai. One of the causes is early marriages and sometime forced marriage among the Maasai girls before they reach are 18 years of age. This is a violation of women and girls right. According Jepkemboi, (2007) early marriage does not only denie a young girl chance to education but violate six main rights of women and girls. These include A) The right to free and full consent to marriage; B) the right not to engage in sexual relations; C) the right to exercise control over reproduction; D) the right to education; E) the right to no labor exploitation; and 6) the right to personal freedom.According to findings of this study one of the reason for early marriages is fear of premarital pregnancy which brings shame to the family and lower the bride price as well as discouraging other girls from continuing with education. This is in line with (Atsiaya, 2010) study which reveal that parent becaome reluctant to educate a girl child because of fear of early pregnancy.

The research has also revealed that when resources are scarce parent will ignore girls and prefer to educate boys because they are seen as a means of continuity in leneage while the girl is on transit. This is in agreement with Sheila, (2006) findings that Education for all by 2015 may not be realised in pastoral communities unless concerted effort are put to change the trend of access to education for a girl child.Murranism is one of the causes contributing to the the Maasai males to drop out of school because of the values, skills and attitudes inculcated through the system. This agrees with Tignor, (1976) findings which revealed that the Indigenous Knowledge instilled during Murrranism are so pervasive and so anithetical to educational receptivity that makes adolescent Maasi males lose interest in schooling.To the girls once they pass rite of passage to adulthood many drop out of school because they are rediculed by their peers for attending school that is seen to be for children. This concurs with Amadi, Role, \& Makewa, (2013) findings concerning the perception among the Maasai females after circumcision.

\section{CONCLUSION}

From the study we conclude the lives of the learners are so apprehensive concerning pastoralism, parent's socioeconomic condition, distance to school and socio-cultural practices. The causes of non-adherence to education are complex both from internal and external problems of the learners. Besides, the crucial problems such as lack of uniform, repeating classes and gender roles.

\section{RECOMMENDATIONS}

In Maasai land schools are far apart necessitating student to walk greater distances to school, which is a threat to security of young girls. Early preganancies and forced early marriages are some of the reasons contributing to high drop out rate in the region. To reduce these circumstances causing high rate of the Maasai girls drop out, it is appropriate to construct schools with dormitories for girls to reduce vulnerability of girls to such factors. The Maasai Association (2015) has been advocating for building of more Schools in the region. The AIC church has been on the forefront in building boarding school for Maasai girls, where some are those rescued from early marriages (World YWCA, 2001).The progression of girls in Maasai land to high school is low and drop out rate is high because some parent can not afford the high fee charged and other necessities required for schooling. This is attributable to poverty, however, sometime parent prefers educating boys when resources are limited. To curb this challenge the government should consider setting aside funds for scholarship for girls from pastoral communities who perform well, so that they can pursue their education beyond primary level (Jepkemboi, 2007).The local leaders should also work together with other stakeholders to enforce women and girls right through participatory for education-in- culture and culture-in-education. Additionally, sensitization programs should be done to the community leaders, administrtors, religious leaders, youth, teachers, female circumcisers and parents to help curb Maasai practices that contribute to high drop out rate (Maendeleo ya Wanawake, 2000).

The Murran system is a vital Maasai institution that contribute to high drop out rate to young males among the Maasai community. The system is good for the community, however, when done during the schooling years of schooling it leads to a marked dis-interest among the Maasai males to School based program. Therefore, Murranism should be delayed to mid twenties when Males have attained secondary education.

\section{REFERENCES}

[1] Amadi, M. A., Role, E., \& Makewa, L. (2013). Girl Child Dropout: Experimental Teacher and Student Perception. International Journal of Humanities and Social Science, 3(5), 124-131.

[2] Atsiaya, P. (2010, May 21). Ten more Girls Pregnant in Nyanza Schools. Retrieved 2015, from http:// www.standardmedia.co.ke

[3] Jepkemboi, G. (2007). Early and Forced Marriages: A Violation of Rights of Women and Girls in Kenya. Advancing Women in Leadership Online Journal, 25, 1-5. 
[4] Juma, A. S., Simatwa, W. M., \& Ayodo, O. M. (2012). Impact of family Socio-economic status on girl students' academic achievement in secondary schools in Kenya: A Case study of Kisumu East District. International educational research, 3(3), 299-310.

[5] Maasai Association . (2015). Maasai High School Project. Retrieved 2015, from http://www.maasaiassociation.org/high-school.html

[6] Maasai Girls Education Fund. (2014). The Need to Eliminate Gender Discrimination. Retrieved 2015, fromhttp://www.maasaigirlseducation.org/the-need/value-of-educating-maasai-women/the-need-toeliminate-gender-discrimination

[7] Maendeleo ya Wanawake. (2000). Improving the status of women. Women's Voice. Retrieved 2015, from http://www.maendeleo-ya-wanawake.org/status.htm

[8] Obanya, P. (2005). Fifth Conference of African Ministers of Culture. Nairobi, Kenya.

[9] Quick-Palmer, A. (2014). Retrieved 2015, from http://www.annas-friends.com/child-marriage-meanmaasai/

[10] Ronoh, A. K. (2008). "Influence of Indigenous Knowledge on the Adoption of School-Based Education Among Kenyan Maasai: Implications for Curriculum Reform.”. Egerton University, Kenya: Unpublished Ph.D Thesis.

[11] Ronoh, A. K. (2008). Influence of Indigenous Knowledge on the Adoption of School-Based Education Among Kenyan Maasai: Implications for Curriculum Reform. Unpublished Ph.D Thesis, Egerton University, Kenya.

[12] Ronoh, A. K., Chiuri, L. W., Matheka, R. M., \& Bor, E. K. (2010). Effects of Murran System's Indigenous Knowledge on Maasai Youth's School Attendance in Narok District, Kenya. An International Multi-Disciplinary Journal, 4(3), 1-23.

[13] Rotich, S. K., Rono, K. J., \& Mutisya, S. M. (2014). University Education of the Maasai Girls in Kenya at Crossroad: A Viewpoint of the Role of local leaders and social-cultural factors. The International Journal of Social Science And Humanities Inventions, 1(1), 51-61.

[14] Sheila, A. (2006). EFA for pastoralists in North Sudan: A mobile multigrade model of schooling and teaching. Springer: Dordrecht.

[15] Tignor, R. L. (1976). The Colonial Transformation of Kenya: The Kamba, Kikuyu and the Maasai from 1900-1939. Princeton, New Jersey:: Princeton University Press.

[16] Tobik, P. P. (2009). Education of girls and women in maasailand. The case study of Kajiado District. Nairobi: Unpublished Master's Thesis, KU.

[17] UNESCO. (2010). Education for all global monitoring report; Reaching the marginalized. Paris: UNESCO.

[18] Vavra, R. (1991). A Tent with a View: An intimate African Experience. New York: William Morrow \& Co.

[19] WHO. (2011). Adolescent pregnancy: Issues in adolescent health \& development. Geneva.

[20] World YWCA. (2001, December). Project spotlight: Child brides. Common Concern Quarterly Magazine,112.Retrieved2015,fromwww.worldywca.info/index.php/ywca/content/download/6886/8054/fi le/cc112.pdf

[21] Yara, P. O. (2012). Determinants of female students' performance in Primary schools in Loitokitok, Nairobi. International journal of business and social sciences, 12(3), 341-378. 